IRA-International Journal of Technology \& Engineering

ISSN 2455-4480; Vol.05, Issue 01 (2016)

Pg. no. 6-11

Institute of Research Advances

http://research-advances.org/index.php/IRAJTE

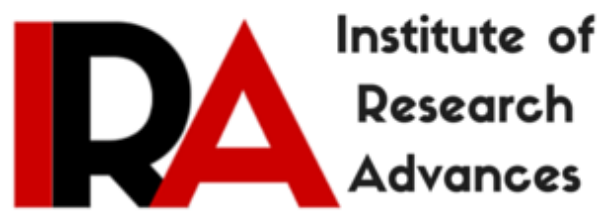

\title{
Design and Development of Acrylic Respirometer for Study of Oxygen Consumption by Fish Seed
}

\author{
${ }^{1}$ B.C. Mohapatra $\&{ }^{2}$ P. Sahoo \\ ${ }^{1,2}$ ICAR- Central Institute of Freshwater Aquaculture, \\ Kausalyaganga, Bhubaneswar- 751002, Odisha, India.
}

Type of Reviewed: Peer Reviewed.

DOI: http://dx.doi.org/10.21013/jte.v5.n1.p2

\section{How to cite this paper:}

Mohapatra, B., \& Sahoo, P. (2016). Design and Development of Acrylic Respirometer for Study of Oxygen Consumption by Fish Seed. IRA-International Journal of Technology \& Engineering (ISSN 2455-4480), 5(1), 6-11. doi:http://dx.doi.org/10.21013/jte.v5.n1.p2

(C) Institute of Research Advances

\section{(cc) EY-No}

This work is licensed under a Creative Commons Attribution-Non Commercial 4.0 International License subject to proper citation to the publication source of the work.

Disclaimer: The scholarly papers as reviewed and published by the Institute of Research Advances (IRA) are the views and opinions of their respective authors and are not the views or opinions of the IRA. The IRA disclaims of any harm or loss caused due to the published content to any party. 


\begin{abstract}
A simple and noble respirometer in acrylic material has been designed and developed by ICARAICRP on Plasticulture Engineering and Technology Centre at ICAR-Central Institute of Freshwater Aquaculture to study the oxygen consumption by fry, fingerling and advanced fingerling stages of fishes. The instrument is transparent, can be completely sealed air tight, and can store water and fish for experimentation. Water can be filled or drained manually at desired intervals, and the inlet and outlet hubs are fixed with screens to protect the fish seed to escape out of the respirometer during experimentation or water flow. Two models of respirometer were fabricated having dimensions of 10 "x 10" 10 " and 11 "x 11 "x 11 "with $18 \mathrm{~L}$ and $22 \mathrm{~L}$ water storage capacities respectively. The components of the respirometer are the transparent water tank with outlet hub containing drainage valve, transparent covering lid with inlet hub containing inlet valve and airway cap. The airway cap is provided in the lid to make a way for air to pass into the tank while draining water or out of the tank during filling of the water. The operation of the respirometer involves filling the tank with water, stocking the fishes, covering it with the lid, taking water samples for oxygen estimation in the start and end of the experiment.
\end{abstract}

Keywords: Respirometer, dissolved oxygen, oxygen consumption by fish seed

\title{
Introduction
}

Global fish consumption has undergone major changes in the past five decades. World apparent per capita fish consumption has been increasing steadily from an average of $9.9 \mathrm{~kg}$ in 1960s to $18.6 \mathrm{~kg}$ in 2010 (FAO, 2012). This increase in demand for fish amongst the world population can be accounted to stronger aquaculture technologies, bridging the supply and demand gap, high income growth of population in developing nations, etc. To cope up with such demands, there is a need to increase the fish production even more compared to current rates. Fish production can be increased by bringing more water bodies in to the aquaculture activities or by adopting hi-tech aquaculture techniques. Supply of quality seed, feed, medicines and management practices are the keys to the success of fish production. Proper stocking density of fish and maintenance of water quality parameters of pond are also equally important for higher fish production. Dissolved oxygen is a major parameter which directly decides the carrying capacity and ultimately the stocking density of the fish in pond (Parker, 2002). Based on the oxygen need of the fish and its availability in system one can decide the stocking density. Though dissolved oxygen can be controlled and regulated with proper use of aeration techniques in pond, but, there is a need for measurement of respiration to gain clear information on the metabolic activities of the livestock commodity (Saltveit, 1995).

Respirometer is any device that is used to measure respiration rates or $\mathrm{O}_{2}$ consumption rates. There are many iterations of this respirometry technique, but the major three types of this system are closed system, flow through system and intermittent flow system which have their own specialty and operation technique (Svendsen et al., 2016). The closed system involves placing the livestock in a sealed container filled with water and collecting the water at a pre-planned interval for study of its parameters.

The respirometer which we have designed for the study of oxygen consumption in fish seed is a closed system one, but with elements of a flow through system. Two prototypes having transparent water tanks of $18 \mathrm{~L}$ and $22 \mathrm{~L}$ capacity with removable leak-proof covering lids were designed and developed. In this paper the respirometer of $18 \mathrm{~L}$ capacity is being explained in detail. There is an inlet valve on the covering lid and outlet valve on the tank wall structure. The main operation involves filling the tank with water and fish seed in various stages and sealing off the tank. Initial water parameters including DO are studied and after a pre-planned interval water is again drained to a bottle/ BOD bottle to study the final parameters including DO, which when compared with the initial gives a clear understanding of the metabolism of the livestock. The equipment is so designed that it can be used to stock fish in all stages of their growth viz., spawn, fry and fingerling, and study their metabolic activities. 


\section{Materials and methods}

Before designing the respirometer, the purpose of the equipment and process to be followed for its operation were planned. The requirement was to build a transparent tank to store water and fish for study, and after stocking of fish the tank needed to be closed with a leak proof lid for sealing purpose. The water is to be drawn at different intervals for study of its parameters. Also, while drawing water it is to be ensured that fresh water is simultaneously filled from the top through inlet valve in order to fill the air gap generated while draining water. Or otherwise the airway has to be kept open. Stocking density in the designed respirometer has also to be planned, because the respirometer : organism volume ratio needs to be kept minimal for ensuring accurate measurement, but leaving a sufficient volume for the comfort and easy movement of the stocked fish (Svendsen et al., 2016).

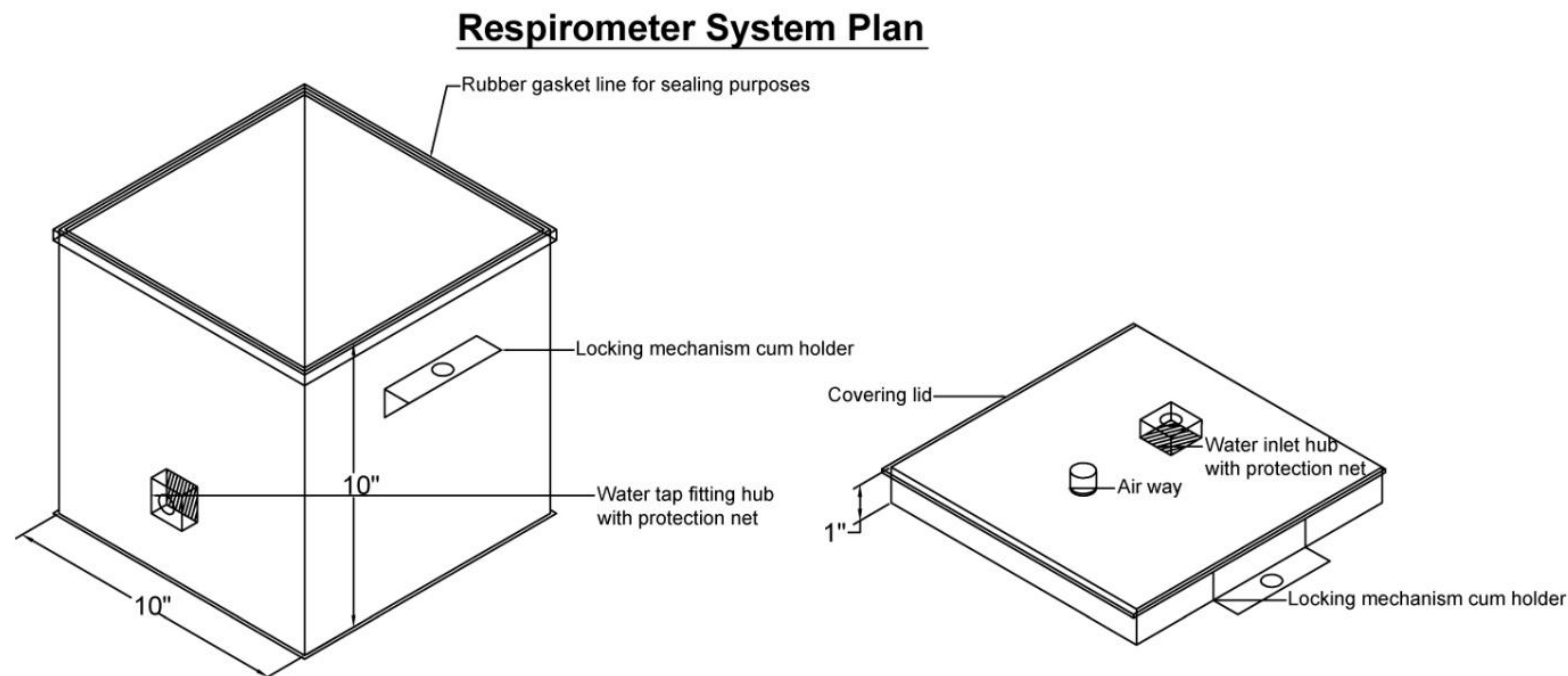

Fig. 1. Design of the Respirometer System

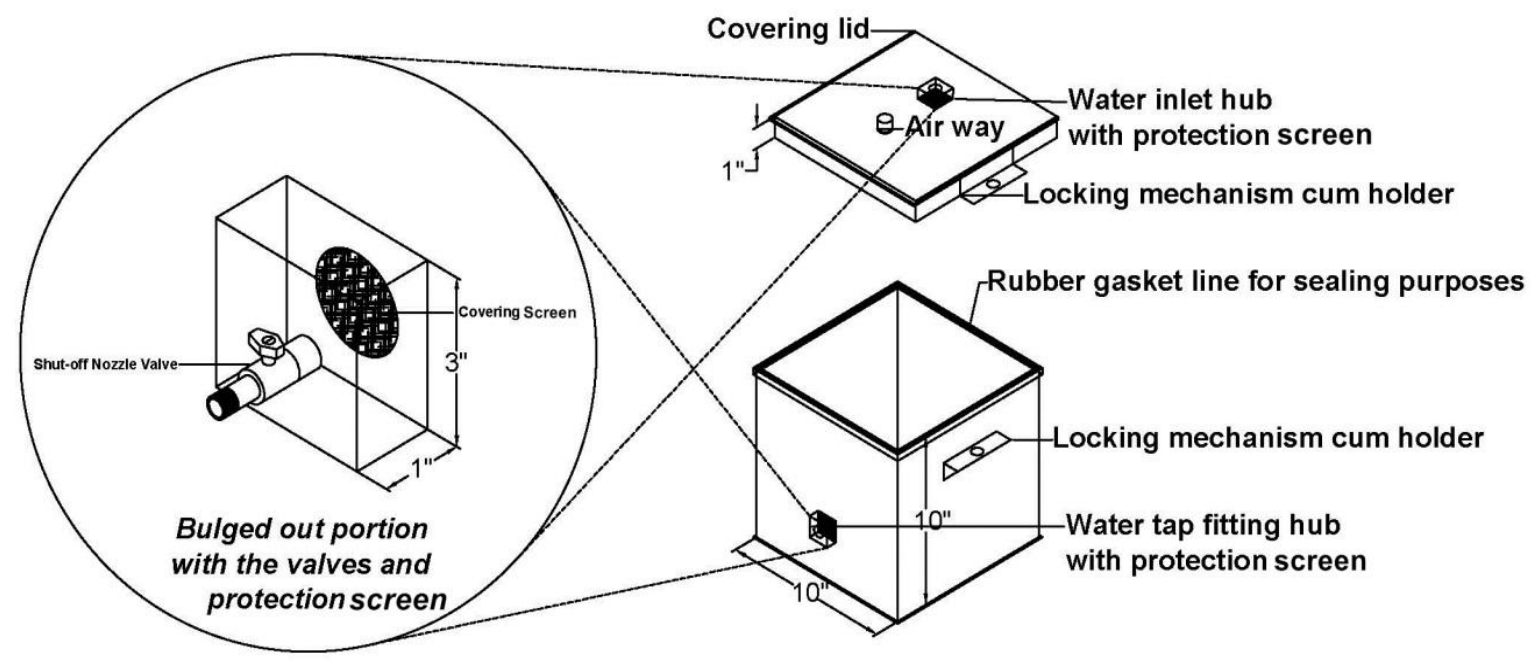

Fig. 2. Inlet and Outlet Hub of the Respirometer

Two respirometers of different water storage capacities $(18 \mathrm{~L}$ and $22 \mathrm{~L})$ were fabricated having dimensions of 10"x 10"x 10" and 11"x 11 "x 11" respectively, but for this paper we have mentioned the fabrication technique of $18 \mathrm{~L}$ capacity respirometer. The respirometer designed of 10 "x 10 "x 10 " dimension was fabricated using clear glass acrylic sheet. A $4 \mathrm{~mm}$ thick acrylic sheet of 4' 6 " $\mathrm{x} 10$ " dimension was procured from the local market. The acrylic sheet was bent as per the required 
dimensions with application of heat to form the tank walls as shown in the design diagram (Fig. 1). The base of the tank was glued to the walls using water proof acrylic glue. A $6 \mathrm{~mm}$ thick acrylic sheet of 1' $x$ 1' dimension was also procured to fabricate the removable covering lid for the tank. The $6 \mathrm{~mm}$ thick acrylic sheet was used for lid because its own self weight can aid in sealing the minor gaps between the bottom surface of the lid and the top edges of the tank walls. But, for actual sealing a rubber/ neoprene gasket was used and fitted on the top edges of the tank walls. The lid was so fabricated that it fitted tightly along the gasket lining and ensured zero air flow into the tank. The lid and the tank were tightened using nuts and bolts in the holder as shown in the design and the picture below (Fig. 3).

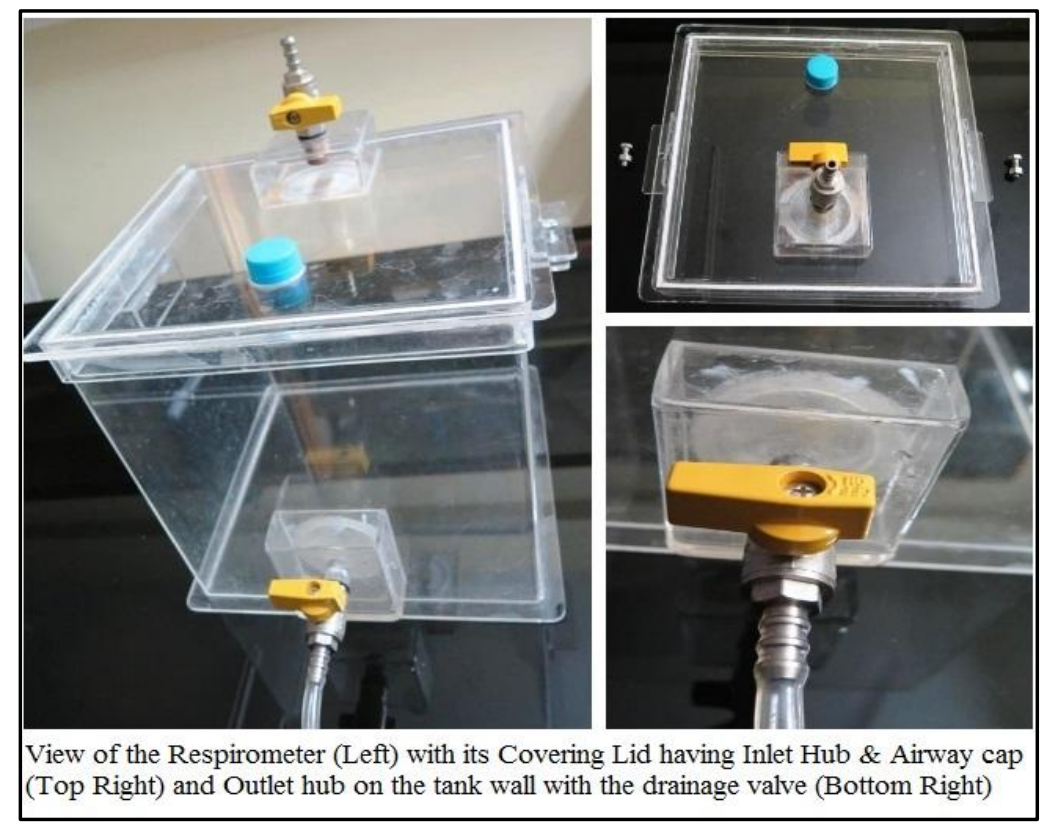

Fig. 3. Developed Acrylic Respirometer

The water flow in and out of the tank was also needed to be regulated as per the requirement. Metallic shut-off nozzle valves were procured and fitted on the top lid surface as inlet and on the tank wall surface as outlet. Fitting the nozzles directly on the surfaces after drilling, it was found out that the rear portion of the nozzles were remaining inside the water, which hindered the free movement of the fishes and affected the fish mortality rate. For this purpose, bulged out portions on the surface of the lid and tank wall to hold the valves were planned and fabricated as per the design shown (Fig. 2). The drilled portions on the inner surfaces of the tank and lid were glued with a nylon mesh so that while draining water the fish seed will not come out. The inlet and outlet nozzles were fitted with silicone pipes for filling and draining water respectively. The length of the silicone pipe from the outlet nozzle valve was kept in such a way that while draining water, the delivery tip will touch the bottom surface of the BOD bottle/ water sample bottle so that bubble formation during delivery will be countered. The step by step process followed for fabrication is hereby mentioned in the flow chart below. 


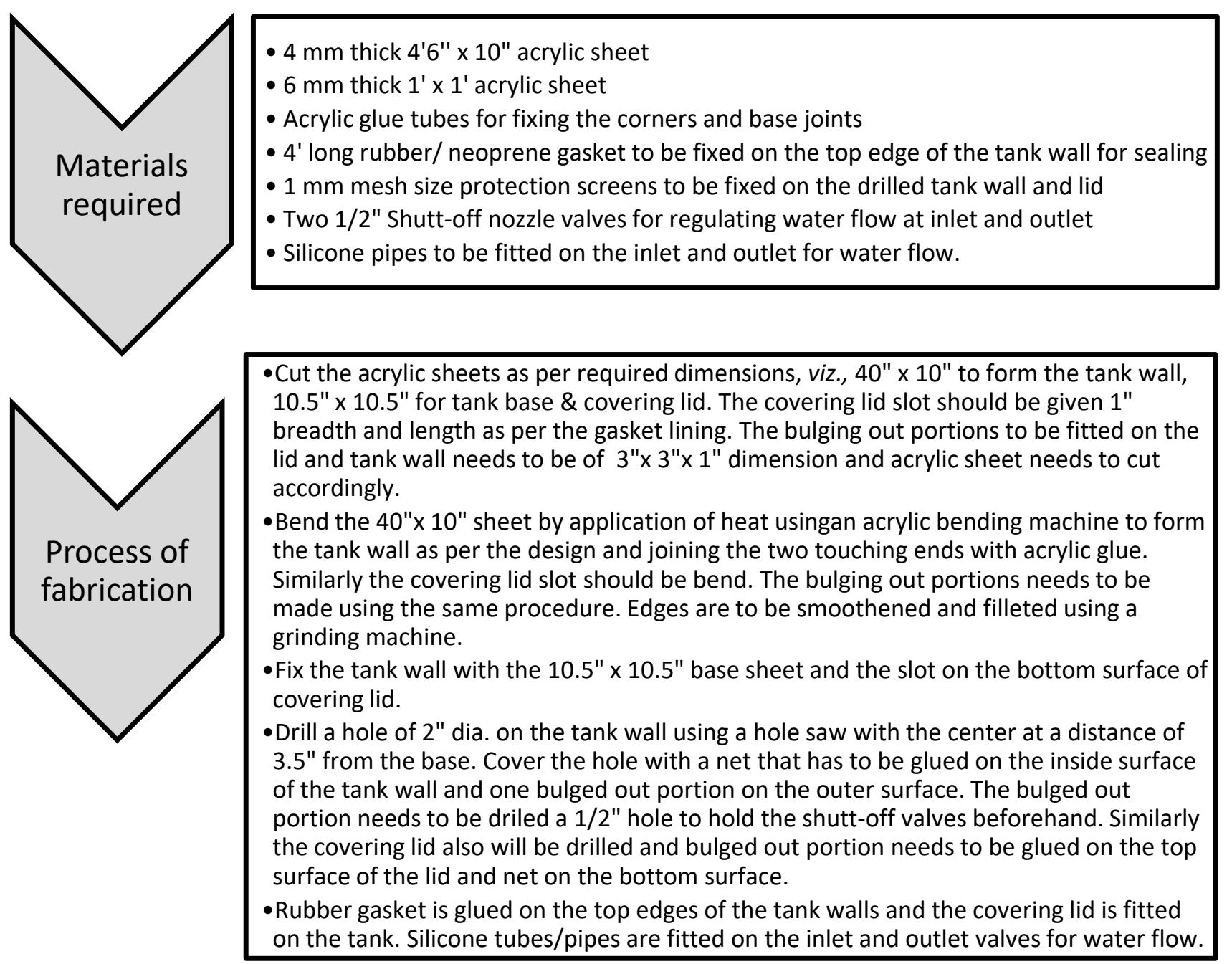

After stocking fish in the tank, the initial parameters like dissolved oxygen, carbon dioxide, etc. of the water needs to be found out. The ultimate work is to drain water from the tank at a particular preplanned interval and study its parameters for finding the dissolved oxygen consumption of the stocked fish and other entities by comparing with the initial parameters.

\section{Results and Discussions}

Many types of experimental setups for study of dissolved oxygen in a sealed condition of water tank have been carried out at different places. Mostly sealed glass jars or bottles (Motwani and Bose, 1957), conical flasks or Erlenmeyer flask (Mohamad, 1982) and thick liquid paraffin as a sealing agent in the glass jars (Thampi et. al., 1994) were used as respirometers. But, those have their own shortcomings. For example, drainage of water from the sealed container after opening the lid is a problem for most experiments done previously. Also, in paraffin seal experimental setup, bringing out the fishes from the tank is an intricate process, because paraffin oil will stick on their body which makes them unusable for further experimentation or rearing. These problems have been countered in the present version of the respirometer.

The respirometer was designed as an equipment to measure and calculate the oxygen consumption of fish. Though a probe of a digital DO meter can be fitted inside the tank to get a real time reading of the oxygen, but the probe will hamper the free movement of fish and also the DO meter requires 
electricity current for its functioning. Therefore, a manual approach of respirometer operation was planned. The process followed for the operation is shown below:

Clean the respirometer tank
Fill the tank with pre-conditioned water
Stock the fishes in the tank
$\vee$
Seal the tank by the covering lid and tighten using the locking mechanism
$\vee$

\section{Conclusion}

The respirometer is a viable equipment to study the oxygen consumption of fish. The design and fabrication was made using local available materials in order to keep it low cost. The performance of the device was found to be satisfactory and it can be concluded that the present respirometer model is a simple and cost-effective non-digital device for study and monitoring the DO consumption of fish in laboratory condition.

\section{Acknowledgement}

The authors are thankful to the Indian Council of Agricultural Research for financial assistance through AICRP on Plasticulture Engineering \& Technology. The authors are also thankful to the Director, ICAR-Central Institute of Freshwater Aquaculture, Bhubaneswar for support and facilities provided to carry out the work.

\section{References}

[1] FAO, 2012. The State of World Fisheries and Aquaculture 2012. Food and Agricultural Organization, Rome, p-3.

[2] Mohamad Kasim, H, 1982. Effect of temperature on respiration of Labeo fimbriatus (Bloch). Indian Journal of Fisheries, 29(1\&2): 85-93.

[3] Motwani, M.P. and Bose, B.B., 1957. Oxygen requirements of fry of the Indian major carp, Labeo Rohita (Hamilton). Proc. nat. Inst. Sci. India (B), 23(1-2): 8-16.

[4] Parker, R.O, 2002. Management Practices for Finfish. Aquaculture Science, $2^{\text {nd }}$ Edition, p- 121.

[5] Saltveit, M.E., 1995. Measuring Respiration Internal Report. University of CA, Davis, CA, p- 5. Svendsen, M.B.S., Bushnell, P.G. and Steffensen, J.F., 2016. Design and setup of intermittentflow respirometry systemfor aquatic organisms. Journal of Fish Biology, 88: 26-50.

[6] Thampi, R., Rattan, P., and Chatterji, A., 1994. Respiratory metabolism in Oreochromis mossambicus, Peters under different environmental conditions. Pakistan Journal of Marine Sciences, 3(1): 9-13. 